\title{
Cavell on Outsiders and Others
}

\section{Citation}

Moran, Richard. Forthcoming. Cavell on outsiders and others. Revue Internationale de Philosophie. Ed. Sandra Laugier.

\section{Published Version}

http://www.cairn.info/revue-internationale-de-philosophie.htm

\section{Permanent link}

http://nrs.harvard.edu/urn-3:HUL.InstRepos:4797082

\section{Terms of Use}

This article was downloaded from Harvard University's DASH repository, and is made available under the terms and conditions applicable to Open Access Policy Articles, as set forth at http:// nrs.harvard.edu/urn-3:HUL.InstRepos:dash.current.terms-of-use\#OAP

\section{Share Your Story}

The Harvard community has made this article openly available.

Please share how this access benefits you. Submit a story.

\section{Accessibility}


Forthcoming in Revue Internationale de Philosophie

Special issue edited by Sandra Laugier1

\section{Cavell on Outsiders and Others}

In Part Four of The Claim of Reason, Stanley Cavell begins to draw out the similarities and differences between the two forms of skepticism that are the focus of the book as a whole, skepticism with respect to the external world, and skepticism with respect to others ('other minds'). ${ }^{1}$ Both forms of skepticism may begin with a sense of my enclosure within my own experience, separated from the object of knowledge, and the sense that my own position for knowledge here (which is not essentially different from

1 In this paper I will be concentrating on a relatively short section of The Claim of Reason (Oxford, 1979), roughly from p. 416 ('The Outsider') to p. 432 ('Confinement and exposure in knowing'), and even within this section there is much that will be touched on hardly at all. (In particular, I will have little to say about the notion of 'empathic projection' which is also being developed in these same portions of the book.) In addition, I will only occasionally be noting the fact that Cavell's own formulations in these pages are expressed in more than one voice, and are subject to questioning and correction as the text progresses. 
anyone else's) is inherently disappointing, doomed to failure. ${ }^{2}$ This very disappointment with my position for knowledge, however, would seem to carry with it the possibility, and perhaps the necessity, of imagining another position for knowledge not subject to these limitations (assuming for the moment that it is correct to picture my position as limited here). That is, if there is something here I cannot know, something inadequate about my position with respect to the facts in question, it seems I should be able to say something about what a better position would be, otherwise it is hard to understand what could be meant by thinking of my own position as falling short. We may begin with a sense of separateness (from the world, from others), which is then experienced in terms of disappointment, and then in certain contexts this is interpreted as a failure of knowledge, indeed a necessary limitation on what can be known. But to understand one's problem as one specifically of knowledge, to address it in those terms and look for a solution in those terms, there should be an imaginable figure, an imaginable position for knowledge, that bridges this separation and gets at the facts themselves. Whether this feat of imagination is ultimately successful or not (about which more soon), the point of it is that spelling out this other position enables me, or forces me, to characterize my own position here, and hence assess the nature of my disappointment with it. In rehearsing skepticism about the external world, I may imagine myself as 'sealed within

2 The 'my' and 'I' in this exposition should, of course, be understood, representatively, replaceable by any person conducting such reflections. Such a point, however, hardly belongs in a footnote since the possibility, or task, of the representativeness of any 'I' is one of Stanley Cavell's great themes. 
my own circle of experience'. I have various experiences, but what I can't know is whether they are of anything, any world, outside of me. And when confronted with such things as the argument that I couldn't tell if I was dreaming or not, I may feel that I am in principle powerless to 'break out' of my own private circle of experience and see how things are on the outside. This sketches out a characterization of my position for knowledge: it says that it is something essentially based on experience, and suggests a certain conception of experience. Experience is the sort of thing that purports to reveal the world to a human subject like myself. But it is also in the nature of experience that it can, as it were, be mimicked. It is possible for me to have a dream or hallucination of a tree in front of me, when there is no tree there at all. And nothing from within my experience itself guarantees a connection with how things are outside it.

Cavell uses the name 'Outsider' to characterize another possible position for knowledge, one that is not either sealed in or sealed out in the way I imagine my own position for knowledge to be. ${ }^{3}$ In the case of skepticism about the external world, we

3 The name 'outsider' for such a position in the setting up of a skeptical possibility appears in Thompson Clarke's 1972 paper, 'The Legacy of Skepticism' in the following terms:

"I can imagine, it seems, that I might be asleep now, dreaming, really in surroundings very different from these. But the moment I am conscious that there will be real surroundings, I realize I'm taking for granted that these environs could be observed, know to be real, by outsiders, if any, in appropriate positions."

p. 766, 'The Legacy of Skepticism', Thompson Clarke, Journal of Philosophy, vol. LXIX, no. 20, November 9, 1972, pp. 754 - 769. On the same page, Clarke also refers to 
may imagine several different figures that could occupy this role. If the problem is that I can't tell whether I'm dreaming, then we could imagine another person watching me sleep, hearing my mutterings about being chased by a dog. This person, outside my experience, knows I'm just dreaming. When Descartes imagines an Evil Demon who systematically arranges his experience to be constantly deceptive, he is imagining the Outsider as the very cause of the skeptical situation. The Evil Demon is standing outside his experience, making sure that he is always in error. But for the Demon to be in that position, and to have those powers, is surely to be in a position to know how things really are in the world. (Assuming there is a world at all in this scenario, and that the universe doesn't consist simply of "me", with or without a body, and this overworked Demon.) Or, of course, the role of the Outsider could be taken by a more traditional God. He doesn't have to be imagined to be responsible for my error, or my inability to emerge from it. If my worry is more personal, the worry that I myself may be hallucinating, or going mad, then the Outsider could be just an ordinary person whom I don't take to share my malady, and who is in a position to correct me. What the idea of the Outsider is, then, is that of a role that may be occupied by several different imaginary figures. And the point of imagining such a figure is that it tells us something, by contrast, about our own epistemic position. Or it reveals to me, by contrast, how I am conceiving of my own epistemic position, when I engage in my skeptical reflections. There is something that I can't know, but there another possible position better than

Descartes' Evil Demon as "the arch outsider". Clarke is, of course, one of the two dedicatees of The Claim of Reason, and Cavell says more about this source in the Foreword, p. xxi. 
mine from which some person, or perhaps superhuman personage, would know.

It is for this reason that the progress of skeptical argument doesn't just permit or encourage the imagining of someone in the position of Outsider, but in an important sense obliges us to do so. Doing so is necessary to keep us honest in the progress of the skeptical argument. For the conclusion of such an argument is supposed to be that there is something, some fact or possibility, that we do not know, and perhaps can never know with certainty. If this is to express a genuine failure of knowledge, a genuine limitation of ours, then we should be able to say what it is that we don't or can't know, and say something about what it would be to know such a thing. And that is what the imagining of the Outsider is supposed to help us with. It is an obligation of the argument because this imagining is part of our discharging the obligation to make sure that we're really talking about a failure of knowledge, rather than incoherently taking ourselves to be imagining some possibility that is in fact no possibility at all. That is, if we start from the assumption that we are investigating a failure of knowledge, perhaps a necessary failure, then it should at the very least give us pause if it turns out in the end that we have no real idea of what it would be to know the thing in question, or even what the missing fact is. Part of the idea of the Outsider is to give greater detail to the idea of a failure of knowledge, by picturing how things would be from an epistemic position not subject to this failure, not limited or enclosed in the way we may feel ourselves to be.

As with tests of imaginability generally, this is, of course, a fallible test. We may picture an Outsider who in fact fails to know anything we don't know. It may look to us in our imaginings that we have pictured a different and better epistemic position than 
our own, when we have in fact done no such thing. 'God' is frequently mentioned occupier of this role, and he or she is an especially attractive and dangerous one for the very reason of the unrestrictedness of his or her power. As a candidate for Outsider, God is irresistible, for who could possibly be in a better epistemic position? Any possibility of knowledge that is for some reason barred to me is by its very nature open to this Being, who surveys past and future, sees our most private thoughts, and whose mind races ahead to the infinite expansion of pi. But for these very reasons imagining what God knows may not really tell us what a coherent possibility for knowledge is. We don't know how God knows things, we don't really know what it would be like to survey past and future, the infinite possible and finite actual. And we have additional incentive here not to worry about imagining something whose workings are utterly mysterious to us. For in the case of God we can, as philosophers, be complacent about our inability to imagine God's knowledge, and not see the danger this poses to our employing this figure in the position of Outsider, because we can tell ourselves that of course we're not supposed to know how God's mind works. And of course it is precisely the essential mysteriousness of the mind of God, the fact that we don't expect ourselves to know anything about how it works, that attracts the philosopher when he is trying to reassure himself that his conception of some possibility really makes sense, expresses a genuine thought. But one thing even God can surely not do is provide the philosopher's meaning for some set of words whose meaning escapes him in the course of his philosophical imaginings.

There are moments in Wittgenstein when he registers the pull of a figure like God 
to play the role of Outsider in our imaginings of what is possible, and what it is possible to know; and where the effort to press God into that service either leads us astray, or breaks down. I take it that he believes it lead us astray when thinking about things like mathematical certainty and infinity, as when (on pp. 225-6 of Philosophical Investigations) he imagines someone saying "True, we can never know what the result of a calculation is, but for all that it always has a quite definite result. (God knows it.) Mathematics is indeed of the highest certainty -- though we have only a crude reflection of it." And, closer to our issue of skepticism about others, I take it he finds that invoking God as Outsider can simply break down in certain cases of imagining how it may be known how somebody meant a certain word (p. 217). If someone says 'Wait for me by the bank', we may ask how he meant the word 'bank' on that occasion. And we may feel that we know where to look to answer such a question definitively, but that we on the outside are unable to peer inside. And one of Wittgenstein's themes is that meaning something by a particular word or by a name is not a matter of any experiences one may have at the time of speaking, and so an inability to know such a thing is not to be remedied by imagining the ability to peer inside at such experiences. Hence Wittgenstein's famous remark in this context, "If God had looked into our minds he would not have been able to see there whom we were speaking of." (p. 217) This thought is not drawing limits to what God can do or know, but is rather a correction of a particular way the role of Outsider is pictured in the context of skeptical doubts about the possibility of knowing the mind of another. The point is then to force us to question whether we have given adequate expression, or even coherent expression, to our doubt 
or disappointment; and hence to question our assurance that what we are confronting here is correctly described as a failure of knowledge. And although Cavell consistently uses the term 'skepticism' to name both sets of possibilities or disappointments, he just as consistently raises doubts about whether either the problem of the external world or the problem of others should be seen as problems of knowledge.

With regard to imagining skepticism about the external world (because, for instance, we may be dreaming, or all we really see are 'ideas' or 'copies' of things and not things themselves (416-7), we picture the Outsider as a position outside my dreamworld, or beyond my circle of ideas and able to compare them with the things themselves. The thought is that we know in general what the difference is between someone sleeping and dreaming, on the one hand, and someone awake and seeing something, on the other; we just don't know how to determine this difference with certainty in our own case(s). So there is a knowledge that we share with the Outsider (about the kind of difference in question), and there is a knowledge we do not share, since we are imagining him as able to settle the question of this difference in a given case, in a way that we are not able to from within our own position. And whatever coherence the skeptical recital has requires both the idea of what we share (to give expression to our confidence about the question at issue here) and what we do not share with the Outsider (to give expression to our sense that answering this question is 
beyond the reach of our finite powers, or our situatedness).

But the skeptical recital regarding other minds is said to be different from this, and with it the possible role of an 'Outsider' figure.

"What I have to imagine him to know is not merely whether a given other is a being or not, but to know something I do not know about how to tell, about what the difference is between human beings and non-human beings or human non-beings. I do not expect the Outsider with respect to me and the external world to know something I do not know about the difference between sleeping and waking, or about whether one thing is a copy of another." (417)

And this seems to mean that the Outsider with respect to other minds must be pictured as having an additional element of knowledge that I do not share with him, for in addition to being able to settle a question regarding a difference which antecedently I understand perfectly well, this Outsider must be imagined as knowing something I don't know about what the relevant difference itself comes to. His position as 'outside' my confinement now threatens the coherence of the skeptical recital, since in endowing him with this knowledge that I do not share with him, I begin to lose my grip on just what question he was invoked to answer. His position as 'outside' is now too far outside my pre-skeptical position with respect to others, and any restriction on his knowledge is imposed by me, which suggests that I am not allowing any genuinely skeptical fantasy to be released.

A further difference in how we may imagine the position of an Outsider with respect to other minds threatens to render him not far outside enough to help the 
skeptic model his reflections. For even if I imagine the Outsider as possessed of an ability I do not have and do not understand, an ability to distinguish the genuinely ensouled humans from the fakes and artifacts, it seems I cannot, after all, fully credit the results of this power I have (barely) imagined for him. At this point we are imagining the Outsider as able (we know not how) to distinguish the genuinely ensouled humans from the fakes.

"But now everything depends on how he sorts me, what he thinks I am. And that is not the question I imagined myself to invoke him in order to answer. With that question, my interest in the status of others vanishes. There is only me and the Outsider." (417)

Somehow, the rehearsal of the conditions for achieving certainty regarding other minds has difficulty limiting itself to the class of cases the skeptic is seeking certainty on, that is, minds other than one's own. This Outsider was invoked to picture the difference between the human-seeming, and the genuinely ensouled, among the possible creatures or creations I encounter, but not to extend itself to pronouncing upon whether my own apparent humanness counts as an instance of a genuine mind. There wasn't supposed to be a question about what side of the line I myself will be classified. To maintain the coherence of my imaginings here, I seem forced to place restrictions on what the Outsider can discern, can pronounce upon, even though the whole point of constructing him was to imagine a position for knowledge that was unrestricted, or at least not restricted the way my own position is. But now here I seem to be claiming a perspective that I cannot be dislodged from, and which I do permit the Outsider to 
challenge.

With respect to the external world, the superiority of the position of the Outsider seemed tolerable or coherent since there, for example, I know what it is to dream or hallucinate, and I know what it is to wake up from a dream. I know, that is, in less devastating cases, what it is to find out that l've been wrong about some matter, and the philosophical question then would be what consequences to draw from my being wrong, whether a skeptical generalization follows from my error (e.g., regarding a "best case" for knowledge). But I cannot know what it would be to discover that l've been wrong to consider myself a human subjectivity, to wake up from that dream. And similarly, while my thoughts and experiences are not always veridical, and while I may even be wrong sometimes about the very identity of some of my thoughts and experiences themselves (for instance, taking my jealousy to be nothing more than simple admiration, or mistaking something cold for something actually piercing me), I don't have any choice but to take my experiences of thought and feeling to be what those things really are. As Cavell puts it, we seem unable to tolerate the idea of an Outsider who would be in a position to correct, e.g., my sense of my own pain:

"What I feel, when I feel pain, is pain. So I am putting a restriction on what the Outsider can know. He can know something about another's pain that I cannot know, but not something about mine. He is not really an Outsider to me. If he exists, he is in me." (418)

How does the position of the Outsider come to seem so different, and more immediately unstable, in the case of other minds skepticism than in the case of external 
world skepticism? What seems to emerge is that as contrasted with external world skepticism, there is a duality of perspectives with respect to the question of other minds. Or rather, the 'problem of other minds' must reckon with the fact that any mind is an 'other' to some other (several others), and a 'self' to some 'self' (just one self). If there is a problem knowledge here, it applies both to my knowing another mind, and the possibility of another mind knowing me. There is the question: How can I know the mind of another? And there is also the question: how can another know my mind? These will be explored in what Cavell calls the Active and the Passive skeptical recitals concerning others. With respect to the external world, there is just me and some fact, some perceptual object, some representative claim to know what's out there. The challenge is: can I get outside my circle of experiences to knowledge of an independent reality? With respect to other minds it may seem that the problem is rather to break into another circle of experiences. But the main point is that the objects of external world skepticism do not have a perspective on what it is to be known. The question of their knowability has to be solved on the side of the knower alone, with no 'confirmation' from the side of the known object. The possibility of forms of skepticism both with respect to knowing an other mind (the 'active skeptical recital') and with respect to being known by an other mind (the 'passive skeptical recital'), will turn out to be crucial for understanding the instabilities in the idea of an Outsider in other minds skepticism, and for understanding what may be distorting in seeing the problem of others as a problem of knowledge in the first place. 
We can express the difference between the two forms of skepticism (and the differing possibilities for something like an Outsider) in the following way. As we saw earlier, from within skepticism about the external world, picturing myself within my circle of experiences, I have difficulty imagining what it would be to break out of this circle, what could possibly lie on the other side. For everything I could imagine would be some object of possible experience, and yet l'm supposed to imagine something wholly other than any possible experience (though of course very much like one too: as similar and as different as a tomato and an experience of a tomato). Anything I can imagine in this way will at the same time be something which I may merely have the impression of. But from within skepticism about other minds, it seems that I very much can imagine the object of the sort of knowledge I seek, the sort of thing that would lie on the other side of the divide, for there is a mind or a subjectivity that is not unknown to me, and which I ordinarily take to be knowable by others, namely my own. To say this much is to stand on the brink of several misunderstandings: the standing temptation of the argument from analogy (since it seems that in my own case at least I have both an inside and an outside perspective on the facts, and hence can observe the corelation between the two and apply that relation by analogy to others), or the idea that I 'experience' my own mind, or that I can point to my visual field as though to distinguish it from another one, and with all of these the idea that I know what it would mean for another to know my mind "the way that I do". Each of these ideas or 'pictures' is a target of Wittgensteinian 
criticism and diagnosis. Still this much seems true: from within skepticism about other minds, I recognize myself as an instance of the kind of thing to be known, whereas with respect to skepticism about the external world I have difficulty imagining the sort of thing the object of knowledge is supposed to be, the thing-in-itself beyond all experience.

Recognizing myself as an instance of what is to be known means both that I have a conception of the sort of thing in question (viz., a mind, a subjectivity) and that I have a conception of what knowing such a thing is like. Both conceptions may be confused, but in one form or another they are what make possible the Passive as well as the Active skeptical recitals. There is no such duality in the case of external world skepticism, and the existence of such a duality in the case of knowledge of minds means that the position of an Outsider will have to be imagined differently. It is this that leads to the idea of restrictions on what this Outsider can know, or discover, or correct in my apprehension of myself, and it is the possibility of such restriction that threatens to compromise the skeptical project.

Prior to explicitly introducing the Outsider figure, Cavell makes an earlier remark on the different possibilities of the two skepticisms ('external world' and 'other minds'), which anticipates the duality of perspectives which characterizes the situation with knowing minds, and with that the possibility of both 'passive' and 'active' forms of the skeptical recital. In his discussion of the 'private language argument', Cavell describes a line of thought in Wittgenstein which would issue in a kind of restriction on carrying through the skeptical recital. He is discussing Wittgenstein's remark (Philosophical Investigations 246) that "it makes sense to say about other people that they doubt 
whether I am in pain; but not to say it about myself.", and he notes that "This seems just to reverse the skeptic's passage that runs: he alone knows what is going on in him." ( $p$. 353). He goes on to say:

"The potential weight Wittgenstein's remark carries against the skeptic is rather that, in speaking of other minds, the skeptic is not skeptical enough: the other is still left, along with his knowledge of himself; so am I, along with mine. (A first difference with respect to the external world is that an essential element of that skeptic's initial condition is absent, viz., that no position for knowing is better than the one I am in. In the case of other minds, it seems to make sense to say that there is a better position; anyway, you do not know there is not.)"

So if there is a "better position" in the case of other minds, and that 'position' is the Other Person, does that mean that this person is playing the role of the Outsider in my skeptical reflections? My own position for knowing him is less than ideal, but I can indeed imagine a superior position, and I can do so without engaging in extravagant imaginings about beings who are not limited the way humans are, for this Outsider is an ordinary creature right in front of me.

If correct, this thought points to deeper differences between the two skepticisms, and can help to explain what seems distorting in seeing the problem of others as initially a problem of knowledge, knowledge of a certain kind of mind. For if I begin by picturing the other person as being in (or rather: as being) the superior position beyond my own skeptical enclosure, I must soon recognize that I myself represent the superior position, the Outsider's position, with respect to any other person and their relation to my mental life. So everyone is both Outsider and Insider, privileged with respect to one mind, and 
for that very reason disprivileged with respect to all other ones. This suggests a further way in which any 'Outsider' figure must be imagined differently in the two skeptical recitals. For it is precisely the 'otherness' that seems to have no parallel in the case of the external world, and which is misinterpreted in the case of knowledge of minds. For an 'other' mind is not a variety of mind whose features I hope to be able to discover. Rather, since I must recognize that I am an 'other' to the rest of humanity, and they each of them is an 'other' with respect to me, I must recognize that any 'otherness' in question here is not a feature of a kind of mind, some property it has which makes it difficult to know. The skeptical recital assumes that there is nothing uniquely problematic about my mind or its knowability, no special feature it possesses, and no such feature that is possessed by any different mind, knowledge of which may be an issue for me. Instead, 'being other' is a purely relational matter, a role or position I occupy with respect to some people, and that they in turn occupy with respect to me. If it is not a characteristic of my mind that it is "other" (and hence especially difficult to know), then I must recognize that "otherness" is no more a characteristic of any person besides myself. It is rather the name of a relation that I bear to them and they bear to me.

I recognize that I can imagine a superior position, because I can imagine the other person's own position with respect to his or her own mental life (assuming, of course, I have correctly identified a genuine human here). And why is it that I can imagine the other person's position, and know it to be superior to my own position with respect to them? That fact needs accounting for, and the answer seems to be because I know my own position with respect to my own mental life, and know it to be superior to 
that of others, any and all others. That is, I begin with the assumption that I bear a special relation to my own mental life, and that my position here is privileged. There then seem to be two further steps to be taken in applying this thought to the possibility of my knowing others. I must first assume that I am not in any way unique in this respect, that anything that is going to count for me as a mind to be known will be something that occupies this privileged position with respect to its own mental life. In this respect, then, I apply what I take to be the case with respect to my own mental life and apply it to all others, both possible and actual minds. All minds represent such a "superior position" with respect to themselves, as contrasted with the position of any minds beyond their own. And secondly, I must assume that I know what counts as knowing a mind because I know what such knowing comes to in my own case. This superior position with respect to some mental life is what any genuine knowledge of a mind must aspire to, be measured by. So then we can imagine putting these thoughts together and reaching the general conclusion that all minds occupy a superior position with respect to their own knowability (are in this sense 'Outsiders' with respect to all others seeking to know them), and that real knowledge of a mental life is what is to be had from this position.

And it is important to these reflections that in imagining this superior position, I am imagining a superior position with respect to exactly one mind and not more than one. I am not, for example, imagining a kind of generalized Outsider/Insider who occupies a superior position with respect to all minds, mine and everyone else's. For I began these reflections from the realization that I can and do know what a superior 
position with respect to mental life would be, because I occupy such a position with respect to my own mental life. This was presented as uncontroversial, and whatever convincingness it has depends on it being a very restricted claim, a claim restricted to exactly one mind. This stage of the reflection is an expression of my separateness, that the "superior position" I claim to be familiar with extends only so far, stops at the boundaries of one self (however such boundaries are to be determined). The claim to occupy this position depends on the restriction of it to a single person; or perhaps we should say is the very expression of what we mean by the singleness of a person, that a person is distinct from other persons.

The following stage of the reflection, the generalization of this thought to the rest of humanity (that all others occupy such privileged positions of their own), is the expression of my commonality with others; the thought that, privileged or not, there is nothing special about my occupying such a position. Both of these stages of the reflection on minds and their knowability may be said to be expressions of the separateness of persons. Whatever is superior about my position is restricted to a single mental life, and everyone else occupies a similarly restricted superior position: distinct from mine, as mine is from theirs. But the language of 'separateness' should be understood in a way that does not itself assume a skeptical interpretation, or even the idea of any distance between persons, anymore than the different parts of a language, for example, are either close to or distant from each other. Rather, they are what they are with respect to one another, in relation to one another. That is, what is meant by separateness or distinctness here is the fact that the rest of humanity can count as a 
collection of 'others' to me for the same reason that I count as an 'other' to all of them. Our separateness consists in the fact that we occupy these roles with respect to each other, not in any further fact about our differences from each other. Even the picture of 'separateness' is misleading here, for what is fundamental is the plurality of selves or minds, that they are many; and not their nearness or distance from one another.

One lesson to take away from the relational nature of 'minds that are other' is that the Active and Passive skeptical recitals form one phenomenon, and cannot be understood in isolation from each other. Bringing this to philosophical consciousness is one of the major achievements of The Claim of Reason, and the ways in which this represents a radical revision of the standard presentation of the "problem of other minds" have yet to be fully explored. The paragraphs above on the two stages of the skeptical reflection were meant to show how the Active recital ("How can I ever know the mind of an other?") depends on borrowings from the Passive one ("How can I ever make myself truly known by an other?"), for it is by reference to my sense of the restricted privilege of my own position, that I understand what is going to count as genuine knowledge here. I have suggested that these borrowings are unacknowledged in the Active recital, or at least that their dependence on the Passive form is not understood. The picture of separateness and sealed chambers in the Active recital presents itself as standing alone, as illustrations of the difficulty in knowing a certain 
kind of mind, rather than as depending on an understanding of my 'otherness' to others, and the conditions on their knowing me. By contrast, the fact that the Active and Passive recitals are part of one phenomenon is what leads us to see that it is a matter of relational roles rather than non-relational characteristics of certain minds "in themselves". And if the primary fact governing the problem of others is the sheer plurality of others, the fact that they are many (rather than later skeptically inflected interpretations of this fact in terms of separateness, distance, or unknowability), then this raises in a new light what would be wanted from an overcoming of skepticism, since the overcoming of plurality itself, and with it otherness, would simply be the capture by solipsism itself. ${ }^{4} \quad$ The fact that there is equally an issue of my own knowability by others (given my outsideness to them, and their dependence on whatever outward signs I may give them or give off) raises anew the question of what knowing means in this context, or what is wanted as knowledge by an other, or of an other. For if there really is room for some doubt or dissatisfaction regarding the apprehension of me by others (given their outsidedness to me, and mine to them), room for feeling unsure that all of this could really count as their knowing me, then this should force me to question

4 This is a point made by Cavell in his essay 'Knowing and Acknowledging' (in Must We Mean What We Say? (Cambridge, 1976)), particularly in his discussion of the 'Corsican brothers' example, one of whom "suffers everything that happens to his brother" (p. 251), but with the result, not that his knowledge of his brother's pain is "immediate" in the desired sense, but that "he is not other in the relevant sense" (p. 253). I am grateful to Katalin Makkai for reminding me of this passage. 
the picture of 'knowing' someone, some mind, that is presented in the Active skeptical recital, where it is a question of knowing a mind distinct from my own. That is, even when I allow myself the most extravagant metaphysical imaginings about telepathic access, or 'peering inside the mind of another', it seems I should also leave room for the question of whether that other person could thereby take themselves to be known under those allegedly "favorable" conditions. Taking seriously the question of being known, and the subject's own 'say' over that question, may make the fantasy of 'peering into the mind of another' seem not just fantastical or out of reach, but as missing the fact of how the knowledge of another is a matter of relatedness or responsiveness to that person, and not, as it were, simply inspecting them or some other thing "inside" them. If the question of a mind's being known or not is not something settled from one perspective only (i.e., that of the questioner on the outside), then fantasies like that of telepathy or 'peering inside' seem more like expressions of mere curiosity at best, and not as expressions of the desire to know another, where this is supposed to mean something parallel to what answers to one's own desire to be known. The very fact of the two forms of skeptical recital here, the active and the passive, each demanding satisfaction, as it were, suggests that the idea of knowledge at stake in the problem of other minds needs correction, since in its standard formulations it is taken exclusively from the one perspective, the Active one (which itself leans on a picture of knowledge inherited from the knowledge of objects).

The fact that the Active and Passive skeptical recitals depend upon each other 
for their sense means that the object of knowledge, the person, plays a role in the question of knowability different from that of other objects of knowledge. For knowledge of persons, there is an issue, not only of making oneself known, but of being able to find oneself in the knowledge that others claim to have achieved, finding oneself in the language framing the descriptions and explanations. The tomato, the planet, and the proton don't have a view on how they are described; there is no issue there of our best theories of these things leaving out some aspect of their existence that matters terribly to them; and our explanations of their behavior do not wait upon their acknowledgment that, 'yes, this must be what I've been doing all along'. But as human beings, as both knowers and things sometimes known, there is the fact that the object of understanding (a person, or a practice) is already an intentional phenomenon, something already constituted by certain forms of description and explanation. And hence what can count as understanding the phenomenon in question can't be settled by, for example, sheer predictive adequacy alone. (In the sense that it might in principle be possible, for instance, to predict the vocal sounds someone will make and how he will "respond" to those of others, without making any reference to the meaning of what anyone is 'saying'.) Near the end of The Claim of Reason, Cavell is concerned to trace "The question of the history of the problem of others", and he notes that "the historical period we are directly interested in [roughly, the European period following upon the scientific revolution] is one in which a "science" of the human was being called for (p. 473). He notes as well the uncertainty at the time, and persisting to the current day, as to whether such a science has indeed been achieved or not, and if so, by which of the competing 
discourses claiming to replace our pre-scientific ways of understanding ourselves and others.

"Suppose what one thinks is that the science of the human has not been established. Is such a one, therefore, to consider that we are still living in a pre-scientific era with respect to the knowledge of humanity so that, for example, what we think of as psychology will bear to some future, real body of knowledge, call it psychonomy, the relation that astrology bore to astronomy?" p. 474

We could think of the future 'psychonomist' here as occupying an Outsider's position with respect to our current ways of understanding ourselves and others. This raises the question, then, of possible restrictions on the position of the Outsider, analogous to those that emerged in the discussion of other minds. There may well be superior positions on the human as such; that is, superior to our best going resources so far. And there are certainly possible epistemic positions on myself individually which are superior in both form and content to my best current understanding of myself. So any 'say' one could claim over the vocabulary within which he or his fellow humans will count as known or understood, will far from unchallengeable. But there is an issue as to whether the terms of success for this Outsider (on the level of discourses now, such as the imagined science of 'psychonomy') can simply be detached from the pressure exerted by the object of his knowledge (in this case me, or us) that it can in principle recognize itself in this knowledge and accept that it is in fact understood. To say this much is not to say where the failure would lie when this acceptance of being known and understood is resisted or refused. It may lie with the Outsider, it may lie with one's own 
recalcitrance, fear of what the new science reveals us to be. ${ }^{5}$

On the other hand, even accommodating these last thoughts, it might still be denied at the outset there is in fact this difference between the skeptical problems concerning the external world and the problem of others, since it could well be denied that the question of knowledge of objects does not admit of this same doubleness and reciprocity of perspectives. After all, it might be said, I myself certainly am an object of sorts. I am an existent thing in the world, a material being that takes up a certain amount of space. So it seems we should say that insofar as I am a physically existent thing in the world, (and it is no minor extent to which this is true), then some physical objects do have a perspective on what it is to be properly known, do have some say in the matter as to what shall count as being known and being understood.

At the same time, however, no one will want to say that, insofar as he is flesh and blood and bone, he maintains a perspective on how his actual flesh, blood, and bone demand to be known and understood. The people who study blood, it's circulation, it's health and sickness, will have everyone's blessing to employ whatever explanatory

5 It is no secret that the history of discourses promising to deliver a 'science of the human' is history of projects of unmasking or disillusion, as though that were the very form of any disciplinary knowledge of the human. Just why this promise so repetitively takes just this form is also a question for "the history of the problem of others", as broached in other of Cavell's writings, beginning with the early essays of Must We Mean What We Say? (Cambridge, 1976). 
system they find best, and no one will claim any particular say in the matter, nor lodge any claim that his physical nature remains unrecognized, or will not yield up its secrets to their theories. What remains, then, to the reciprocity of perspectives when it is a question of knowing another person? Perhaps we should say that what these considerations show is that what we think of as a mind (as opposed to anything else, including, for instance, a brain) is just that, or that aspect of one's existence, about which the subject claims a say with respect to the terms in which it shall count as understood, or where the phenomenon to be understood (a person, a text, a practice) includes an understanding of itself as a constitutive element. It may be that the Real Distinction between the mind and the body, or between Culture and Nature, comes to this question of where, in what spheres of life, we can claim or aspire to any such constitutive role in determining what shall count as being known or understood; or any place in the world where the desire for knowledge meets a reciprocal demand for recognition. ${ }^{6}$

Richard Moran

Department of Philosophy

$6 \quad$ "This paper provides a further occasion to recall with pleasure and gratitude the experience of teaching The Claim of Reason with Stanley Cavell at Harvard in the Spring of 1997. Recent conversations about all these issues with Martin Stone, Ed Minar, and Katalin Makkai were invaluable to me in seeing this through. 
Harvard University 